\title{
The Effect of Age on Spinal Range of Motion: A Review
}

\author{
Janine Bryant $t^{1,2^{*}}$, Jeff Russell ${ }^{4}$, Yiannis Koutedakis ${ }^{1,5}$, and Matthew Wyon ${ }^{2,3}$ \\ 1School of Performing Arts, Faculty of Art, University of Wolverhampton, UK \\ ${ }^{2}$ Research Centre for Sport, Exercise and Performance, Institute of Sport and Health Sciences, University of Wolverhampton, UK \\ ${ }^{3}$ National Institute for Dance Medicine and Science, Birmingham, UK \\ ${ }^{4}$ Ohio University, Department of Athletic Training, Athens, Ohio, USA \\ ${ }^{5}$ Department of Sport Science, University of Thessaly, Trikala, Greece
}

${ }^{*}$ Correspondence to: Janine Bryant, School of Performing Arts,University of Wolverhampton, Gorway Rd, Walsall, West Midlands, UK WS1 3BD; E-mail: J. Bryant2@ wlv.ac.uk

Received: March 18, 2018; Accepted: April 23, 2018; Published: April 27, 2018;

\begin{abstract}
Reduced spinal mobility may result in activity limitations and participation restrictions, which could subsequently affect quality of life. This literature review examined the effects of aging on spinal range of motion (ROM). Two databases (PubMed and Google Scholar) were searched using the MeSH terms spine, aging, range of motion, athlete, human and collagen. Two hundred twenty-four articles were identified; 210 of these were rejected as not directly relevant with the current review. The accepted articles $(n=14)$ were categorized into four participant groups (athletes, clinical, elderly, and general). Each of the studies was analyzed and assigned a quality grade using the GRADE system provided by the American Dietetic Association. The results suggested that aging causes increased risk for spinal fractures and loss of ROM and bone density. For women, spinal deformity and vertebral compression fractures may lead to impaired mobility and quality of life. More research is needed on the effects of the aging spine in relation to overall health, quality of life and socio-economic status.
\end{abstract}

Keywords: aging, spinal, range of motion, human, athlete, collagen

\section{Introduction}

Musculoskeletal function is determined by range of motion (ROM), strength, endurance, coordination, and sensation [1]. The majority of these physiological parameters (e.g. aerobic power, strength, endurance, coordination, and sensation) peak in late adolescence and then gradually decline with age [2]. Within the musculoskeletal system, part of the aging effect is the increase in intramuscular connective tissue stiffness which results in decreased ROM and a gradual performance decline in Activities of Daily Living (ADL) [3].

\section{Range of Motion in Different Populations}

The changes that occur with aging, such as loss of lumbar flexion, extension and lateral flexion, may be responsible for decreases in spinal ROM [3,4]. The motion profile of physically active or athletic populations is more difficult to evaluate than the profile of less active populations because age-associated differences in the degree of muscle damage after exercise in well-trained humans have yet to be clearly demonstrated in the literature [5].

Yukawa et al reported mean spinal flexion of $53.0^{\circ}$ and hyperextension of $23.4^{\circ}$ with no difference between the genders [6]. Another study reported females decreasing extension and flexion ROM slightly more than males between the ages of 20-70 years $\left(13.9^{\circ}\right.$ and $9.0^{\circ}$ vs $16.3^{\circ}$ and $\left.8.0^{\circ}\right)$ [4]. Age-related reductions in lumbar flexion, extension and lateral flexion were most evident after approximately 40 years of age.

\section{The role of collagen}

It is important to understand the role of collagen and how agerelated changes to collagen matrices are linked to the declining mechanical properties of aging bone and joints [4,7]. Physical and biochemical changes occur to collagen with increasing age, resulting in decreased extensibility. These changes include an increased formation of intramolecular and intermolecular cross-links that restricts the ability of the collagen fibres to move past each other as tissue length changes [3]. Cross-linking involves two different mechanisms, one a precise and enzymatically controlled cross-linking during development and maturation and the other an adventitious non-enzymatic mechanism following maturation of the tissue. This non-enzymatic cross-linking, known as glycation, is the major cause of dysfunction of the collagenous tissues in old age.

The process of cross-linking and the presence of advanced glycation end products (AGEs) seem to be major determinants in the loss of ROM and strength [8]. AGEs naturally form inside the body when proteins or fats combine with sugars (glycation). This non-enzymatic reaction affects the normal function of cells, making them more susceptible to damage and premature aging. The effect of glycation on cell-matrix interactions may be an equally important aspect of aging collagen. It is interesting to note that this process is accelerated in diabetic individuals due to higher blood glucose levels [9]. Although there are 19 genetically distinct human collagens, the functions of the more minor collagens have yet to be clarified. Types 
I and II collagen are found in intervertebral discs. Aging causes this type of collagen to transition into a more fibrotic tissue.

This increased fibrosis, which is associated with degeneration, contributes to changes in material properties of the nucleus pulposus from a fluid-like to a solid-like material, thus contributing to a more brittle, fragile disc [10]. Fragility of aging bone may be related to changes in collagen as evidence suggests that altered collagen molecules have a detrimental effect on the mechanical properties of bone. When bone collagen is damaged due to non-enzymatic cross linking, also known as glycation, the bone exhibits increased stiffness, ROM, decreased bone strength and reduced stability [6].

\section{Aging and hyaline cartilage}

The aging process similarly affects muscles, hyaline cartilage and joint motion. Muscle fibers atrophy and cartilage dehydrates, causing a loss in elasticity and joint motion restriction that leads to flexibility decrease and loss of ROM. The articular surfaces of the human spine's facet joints are covered by hyaline cartilage that serves as an elastic load-bearing material responsible for the frictionless movement of the surfaces of articulating joints. As the structure of hyaline cartilage changes, there is an increased risk of joint inflammation and arthritis [11]. The decrease in tensile strength after the third decade of life, along with inflammation from repeated injury, overuse in sport, and congenital defects may lead to increased risk of osteoporosis $[10,12]$.

\section{Aging and loss of bone mass}

The aging spine is characterized by two parallel but independent processes: development of degenerative discogenic changes and bone mass reduction. osteoporosis, or reduced bone mineral density, increases the risk of stress fractures [13]. In focusing on the relationship between these two processes, the American College of Sports Medicine underlines the need for further research on osteoporosis [14]. One study evaluated factors related to spinal mobility in patients with postmenopausal osteoporosis [15]. The researchers found that skeletal fractures are an important clinical manifestation of the disease, with older female patients the most severely affected. Multiple vertebral fractures can result in postural deformities, which could cause significant functional impairments in ADLs [15,16] and have a significant impact on quality of life.

\section{Joint Hypermobility}

Another important consideration connected to bone health is joint hypermobility, which is defined as excessive range of motion with a global, whole-body score of 4 or higher on the 9-point Beighton scale $[17,18]$. When considering spinal ROM and aging, available motion in the lumbar spine drops by approximately $30 \%$ between youth and age $70[2,19]$. According to Day et al. [20], available hypermobility data in general populations are conflicting; they state that some findings report reduced bone mineral density in hypermobile participants, while others report increases. A study on hypermobile 34-year old women not only found significantly lower bone mineral density measurements, but some of the participants had already reached osteoporotic levels [20].

\section{Characteristics of the aging spine}

Important characteristics of the aging spine include a decrease in collagen and proteoglycan content of the annulus fibrosus and nucleus pulposus [21], damage to collagen from cross-linking [22] and atrophy of type II muscle fibres. This damage results in a decrease in elasticity and joint motion restriction that leads to a decrease in flexibility and loss of ROM [11]. In addition, increased intramuscular connective tissue stiffness can result in decreased ROM [3]. Long-term complications associated with aging affect spinal health and can cause significant functional impairments in activities of daily living [15,16]. Since spinal health and mobility are key determinants of whole body function, an increase in participation restrictions may result in a perceived quality of life change that is usually detrimental [23].

To our knowledge, no systematic review exists that examines the relationship between aging and spinal ROM. Therefore, the aim of this review was to investigate the role of aging and its effects on spinal range of motion, with a deliberate focus on athletic, elderly, clinical and general populations.

\section{Methods}

Two databases were searched (PubMed and Google Scholar) between July and September 2013 and again in September 2017, using the following Medical Subject Heading (MeSH) terms: spine, aging, athlete, range of motion, human, collagen. Research studies were rejected if they did not meet the one of following criteria: English language, human participant, observational study, longitudinal study and case study. The initial search produced 224 articles of which 21 were immediately removed for being animal studies. A further 132 were removed for being unrelated to the MeSH terms and 11 articles were removed because they were not applicable or did not meet the quality requirements of the ADA (American Dietetic Association) Evidence Manual. The remaining 60 studies were rated on a scale of 1 to 3 , with 3 being the lowest quality (Limited), 2 being studies with minor methodological concerns (Fair) and 1 being the highest quality with strong design and free from bias (Good). Studies not meeting these criteria were excluded. An additional 46 articles were eliminated as they either did not pertain to the question being addressed, or were inconclusive in their findings (Table 1). Of the 14 retained papers, 6 were review articles and were manually checked to identify any missed studies that may have related to the subject; none were found. The accepted articles were categorized into the following populations: athletes, clinical, general and elderly. The athlete group consisted of all studies mentioning the word athlete, sports or exercise. The clinical group included clinical trials or research and the elderly group included studies mentioning the term elderly or aging populations. The general group consisted of all other studies which did not fall into the athlete, clinical, or elderly categories (Figure 1).

\section{Results}

\section{Athlete population}

Although the athlete category yielded four papers specifically mentioning athletes, exercise, sport, competition and sports injuries, useful information was gleaned from only one paper relating 


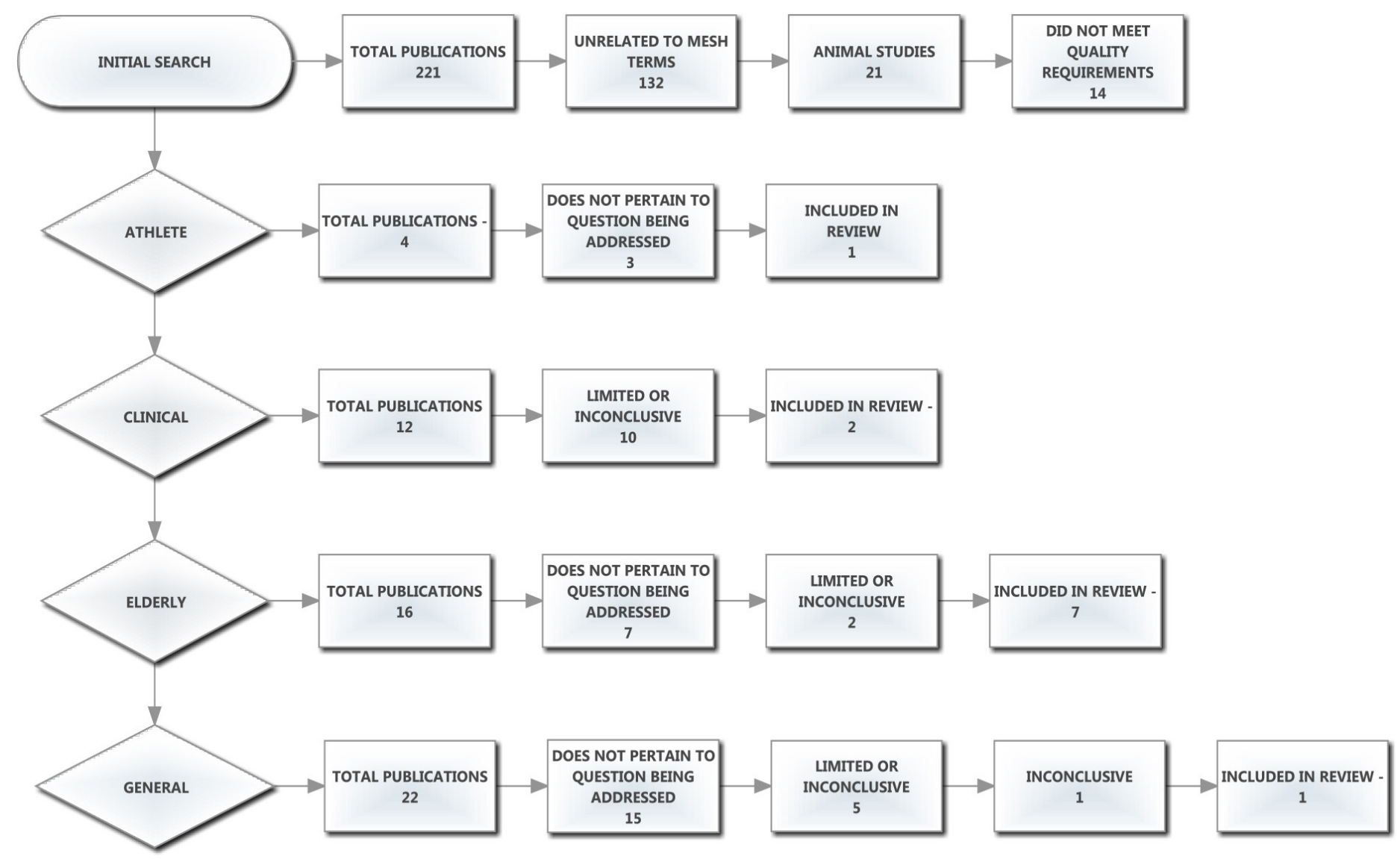

Figure 1: Prisma and exclusion flow chart here.

Table 1: Categories table

\begin{tabular}{|c|c|c|c|c|c|}
\hline Article & Participants & Method & Quality Grade & Significance & Conclusion \\
\hline 8 & $\mathbf{A}$ & $\mathrm{R}$ & II & Focus on degenerative & Role of enthesopathies in ROM changes \\
\hline 27 & G & MR & II & Poor cellular nutrition & Tissue degeneration leads to osteoarthritis \\
\hline 40 & $\mathbf{E}$ & $\mathrm{O}$ & II & Focus on aging spinal disorders & Link spinal disorders to ROM loss \\
\hline 16 & $\mathbf{E}$ & $\mathrm{R}$ & II & Focus on structural changes due to age & $\begin{array}{l}\text { Further study is crucial for understanding the unique biomechanical } \\
\text { function of the aging spine }\end{array}$ \\
\hline 23 & $\mathbf{E}$ & $\mathrm{R}$ & II & Age-associated conditions & Implications on elderly limited mobility and Quality of Life \\
\hline 43 & $\mathbf{E}$ & OBS & I & $\begin{array}{l}\text { Compares healthy and ageing degenerated } \\
\text { discs }\end{array}$ & Connects endplate damage to Degenerative Disk Disease \\
\hline 13 & $\mathbf{E}$ & OBS & I & Aging disc and collagen changes & Both collagen and proteoglycans undergo age-related changes \\
\hline 33 & $\mathbf{E}$ & $\mathrm{R}$ & II & Age is a primary risk for dev. Of OA & $\begin{array}{l}\text { More data is needed to understand age-related changes that lead to } \\
\text { Osteoarthritis }\end{array}$ \\
\hline 49 & $\mathrm{C}$ & $\mathrm{R}$ & II & $\begin{array}{l}\text { Collagen changes and joint function } \\
\text { relating to } \mathrm{OA}\end{array}$ & $\begin{array}{l}\text { Aging impacts reparative abilities that can lead to Osteoarthritis and } \\
\text { loss of ROM }\end{array}$ \\
\hline 42 & C & OBS & I & Links muscle atrophy with low back pain & Pilates improves ROM in trunk and pelvic segments \\
\hline
\end{tabular}

Key: A: Athletes G: General E: Elderly C: Clinical

Methodology: R: Review MR: Mini-review O: Overview OBS: Observational 
to ROM or exercise in relation t.o biomechanical function and aging. The review by Benjamin et al. [24] discussed the structurefunction correlations of entheses on both the hard and soft tissues with attention paid to mechanical factors that influence form and function. It explored the relationship between entheses and exercise, and emphasized the degenerative, rather than inflammatory nature of most enthesopathies (pathological changes at an enthesis) in sport. This study is relevant because, as stated by the authors, the tendonligament complex response to loading allows for multi-axis bending, such as in the lumbar spine. It applies to diseases associated with the spondyloarthritides (SpA) including ankylotic spondylitis, psoriatic arthritis, reactive arthritis and undifferentiated $\mathrm{SpA}$, all of which may have deleterious effects on ROM [24]. The removed papers addressed bone formation and fracture healing, evaluation of changes in T1rho and T2 relaxation time in the meniscus using 3.0 T MRI in asymptomatic knees of marathon runners, tissue engineered strategies for skeletal muscle injury and post-meniscectomy qualitative risk analysis considering high BMI and pre-existing osteoarthritis.

\section{Clinical population}

In the clinical category, osteoarthritis (OA) was discussed in one of the three retained papers. In their review, authors Sinkov and Cymet [25] discuss imbalance of joint function as an initiator of the disease process worsened through changes in the collagen in the joint. The authors describe OA as a non-inflammatory disease characterized by progressive loss of joint articular cartilage resulting in pain and deformity and most present in populations over the age of 65 , an element that can significantly affect quality of life (QoL). Some risk factors for primary OA include increasing age or history of injury to the joint from trauma, repetitive stress or inflammation.

The prevailing explanation for the onset of $\mathrm{OA}$ is a progressive fatigue failure, or prolonged wear and tear $[12,15,25,26]$. This explains the increase in incidence of $\mathrm{OA}$ with age, as well as its prevalence in joints that are overloaded or overused, such as the ankle in ballet dancers [10], or the elbow in baseball pitchers [25].

The second paper in this category discusses lumbopelvic flexibility and stability as affected by Pilates training utilizing forty healthy male and female volunteers with a mean age of $31.65 \pm 6.21 \mathrm{yrs}$ [27]. The study was retained not because it utilized Pilates as a therapeutic measure, but because it examined asymptomatic individuals exhibiting an inability to control lumbo-pelvic stability; this may be an early detection sign for spinal problems [27]. This study indicated that Pilates could be used as an adjunctive exercise program to improve flexibility, enhance control-mobility of the trunk and pelvic segments and, more relatedly, may also prevent and attenuate the predisposition to axial musculoskeletal injury.

The third study [8] examines the effect of strenuous exercise on the turnover rate of collagen and included a discussion on the molecular mechanisms involved in the aging of collagen, increase in stiffness and the process of enzymatic and non-enzymatic collagen cross-links. The authors reported age-related changes in bone, tendon, articular cartilage and the matrix protein glycation leading to formation of intermolecular cross-linking, thereby affecting optimal mechanical functioning of tissue. This process clearly has relevance to aging and exercise because the slow turnover of aging collagen results in an accumulation of advanced glycation end-products. This also can be described as an oxidation rendering the collagen fibres too stiff for optimal functioning. This publication is somewhat limited in that its findings showed that, although strenuous sports training regimes increase tensile strength of bone and tendon, further understanding of the mechanisms of collagen turnover and cross-linking are needed to improve understanding of the problems caused by exercise and injury recovery [8]. The paper was ultimately retained in our study for its focus on glycation and the aging of connective tissue via the process of collagen cross-linking.

\section{General population}

The first of two studies retained in this category, identified as mini-review, addresses transport properties of cartilaginous tissues in relation to their cellular nutrition as it applies to articular cartilage. Poor cellular nutrition in cartilaginous tissues is believed to be a primary source of tissue degeneration that results in $\mathrm{OA}$ or disc degeneration [4]. Transport properties include:

1. Solute diffusivities that are significant because, due to the avascular nature of cartilaginous tissue, diffusion of solutes through the tissue extracellular matrix plays an integral role in cellular nutrition;

2. Hydraulic permeability as an important property of cartilage because water is the major component of the tissue and is an important factor governing the rate of fluid transport; and,

3. Effect of mechanical loading of tissue that significantly affects the transport of fluids and solutes through the tissue, but is dependent on the type of loading (i.e., dynamic vs. static loading).

Intolo et al. [10] focused in their review on the effect of age on lumbar ROM. They stated that, although lumbar ROM reduces with advancing age, it is still unclear how this reduction occurs across different age categories. Furthermore, they stressed the importance of determining if movement reduces with age and whether it does so consistently across different age strata. There were several limitations in this study including that some relevant published studies were not identified due to either alternative keywords or poorly worded abstracts. However, the paper was retained herein for its potential value to clinicians by providing normative data on the expected loss of lumbar ROM in healthy aging individuals. The article demonstrated age-related reductions in lumbar flexion, extension and lateral flexion, losses in flexibility that are most evident after approximately 40 years of age.

\section{Elderly population}

Eight papers were found on the aging process of the spine or musculoskeletal system. The first was an overview discussing aging on intervertebral discs (IVDs), endplates, facet joints, muscles and ligaments, and the vertebral body. Papadakis et al. [28] linked a number of painful disorders to aging of the spine, including loss of bone mass, disc degeneration, facet degeneration, disc bulging, facet hypertrophy and ligamentum flavum hypertrophy. These may contribute to compromised biomechanics and ROM loss. 
The second paper [29], reported an overview of the mechanisms of aging in the spine that cause structural changes and injury risk affecting biomechanics and ROM. However, the review did not address other mechanisms of degeneration beyond advancing age, stating that further study is required to understand the mechanisms of degeneration and the unique biomechanical function of the aging spine.

The third paper retained from the elderly category focused on aging in the musculoskeletal system [30]. The paper focused mainly on age-associated conditions involving the bones, muscles and peripheral joints; the research was broader in that it included musculoskeletal disorders and a range of interactive conditions such as fibromyalgia and tendinopathy that affect soft tissues, tendons and ligaments, bones and osteoporosis, IVD, and muscular conditions like polymyalgia and myopathies. Implications of musculoskeletal disorders on the public health of elderly persons from the perspectives of physical and social impacts caused by pain was presented, including limited mobility and reduced QOL [30].

An observational study was found [22] which aimed to investigate the presence, localization and abundance of cells expressing notochordal cell markers in human lumbar discs during degeneration. Postembryonic vestiges of the notochord were found in the nucleus pulposus of human IVDs. This research suggests a correlation between cells with an immuno-histochemical notochordal phenotype that do not exhibit typical morphology of notochordal cells and early degenerative changes, particularly granular matrix changes. The researchers studied two groups of specimens, the first being lumbar motion segments that were removed from 30 deceased individuals between 26 weeks of fetal gestation and 86 years of age.

None in this group had a known history of back problems or pain. The second group was comprised of 38 disc samples that had been obtained during surgery for painful lumbar disc degeneration and/or disc herniation (protrusion, extrusion, or sequestration). The samples were obtained from individuals (23 males, 15 females; age range 2669 years) with known clinical symptoms, radiological features, and histological degree of disc degeneration.

The loss of cells with typical notochordal phenotype (physaliferous) and the coincident onset with signs of disc degeneration leads to speculations about their role in the preservation of disc function. Although interspecies comparison-premature loss of notochordal cells from chondrodystrophic breeds with higher incidence of intervertebral disc degeneration-gave some support for this idea. This study, was promising as the first study analyzing the presence of cells with notochordal phenotype and age-related changes of adult human discs. However, the authors state that conclusive evidence for this hypothesis is still missing and, therefore, this paper was ultimately removed.

According to Rajasekaran et al. [31], chronic overuse of the immature spine is related to endplate damage leading to degenerative disk disease (DDD). This study was observational in nature, focused on DDD and discussed decreased nutrition as the final common pathway for DDD and endplate (EP) damage. EP damage affects diffusion and, therefore, disc nutrition. The authors found that damage to the endplate may be the initiating factor for disc degeneration by both altering the mechanical environment and affecting the nutritional pathways. This study is also the first in literature to document the feasibility of pharmacological modulation of endplate vascularity and disc diffusion, but is purely a radiological assessment of degeneration, thus, the clinical symptoms have not been considered. Another limitation of the research is that disc degeneration, being an ongoing phenomenon, requires a serial longitudinal and in-vivo study, which, as stated by the authors, was not performed. It would have been useful to have histologically supportive data to explain the changes in the endplate and nucleus pulposus.

Research by Singh et al. [32] discussed age-related changes in the human intervertebral disc. The aim of this study was to characterize age-related changes in the matrix of human intervertebral discs from the third to eighth decade of life with a focus on collagen and proteoglycan composition. It utilized background data of disc degeneration as associated with changes in the concentration and fragmentation of matrix molecules. Forty-six discs of human thoracolumbar spines (T11-L5) aged 32 through 80 years were analyzed. However, the authors did not include the youngest age group (31-40-years old) in their analysis because it is difficult to obtain IVD specimens in this age group due to the relatively low rate of mortality. DNA, collagen and proteoglycan contents were measured using chemical assays while small non-aggregating proteoglycan levels were analyzed by comparative Western blotting. The paper concludes that large proteoglycans play a major role in water retention, while small proteoglycans regulate formation of the extracellular matrix. During aging, proteoglycan and collagen levels decrease, while some small proteoglycans show differing patterns of changes in both the inner and outer nucleus pulposus and annulus fibrosus. The concentration of biglycan increases in all three disc compartments with age, while decorin content declines. The decrease in total collagen and proteoglycan content may increase susceptibility in IVD degeneration. The authors concluded that the functional significance of these changes needs further investigation.

The seventh study found in this category was a review that discussed age related changes in the musculoskeletal system and the development of osteoarthritis [12]. Although this paper duplicated much of what was collected from other studies in this category, this is the first paper to mention Vitamin D deficiency as a risk factor for OA (possibly contributing to oxidative stress symptoms). In addition, this study links formation of advanced glycation end products (AGEs) to the modification of collagen resulting in increased cross-linking of collagen molecules. Formation of excessive collagen cross-links affects the biomechanical properties of cartilage resulting in increased stiffness, more brittle cartilage,and increased susceptibility of the tissue to fatigue failure.

The eighth and final study [33] aimed to establishing radiographic standard values for cervical spine morphometry, alignment, and ROM, and included 1,230 asymptomatic male and female subjects between ages 30 and 80 . Subjects underwent anteroposterior (AP), lateral, flexion and extension radiography of the cervical spine. AP diameters of the spinal canal, vertebral body and disc were measured at each level from the $2^{\text {nd }}$ to the $7^{\text {th }}$ cervical vertebra (C2-C7), with 
sagittal alignment and ROM during flexion and extension calculated using a computer digitizer. Findings included the AP diameter of the spinal canal and disc height decreased gradually with increasing age as well as extension ROM decreasing more than the flexion ROM, and lordotic alignment progressing with increasing age. In addition, the study found there was a significant difference in C2-C7 alignment and ROM between males and females, with cervical lordosis and thoracic kyphosis increasing more with age in females than in males. Although the study had several limitations, including possible measurement errors, difficulty in achieving uniform positions of the vertebrae in relation to the X-ray beams in different positions of motion and measurement being performed only once due to the large sample size, it was ultimately retained in our review as it establishes standard values and age-related changes in cervical anatomy, alignment and ROM (Table 1).

\section{Discussion}

Reduced spinal mobility may result in activity limitations and participation restrictions, which could subsequently affect quality of life. This literature review examined the effects of aging on spinal range of motion (ROM). This research relates to current available research and offers a deeper inquiry into spinal ageing specifically. When investigating how the spine ages, there were several significant subcategories found in the literature. Among those specific to aging, were aging and articular cartilage, aging and flexibility/ROM, aging of specific spinal regions (cervical, thoracic, lumbar), special considerations of the aging athlete, aging and osteoarthritis, aging and muscle strength, bone and aging, and the role of collagen in aging and ROM. In considering ROM and aging, entheses were discussed as common sites of overuse, exploring the relationship between entheses, enthesopathies and exercise drawing attention to degeneration rather than inflammation as histological evidence of the most common enthesopathies rarely demonstrates evidence of inflammation within the affected entheses. In this respect, spinal ROM is affected because the tendon-ligament response to loading allows for multi-axis bending, such as in the lumbar spine [26]. With regards to specific pathologies related to ROM and aging, osteoarthritis, being noninflammatory, causes joint pain and damage which is progressively degenerative, the clinical presentation being deep localized pain with stiffness, especially in OA of the spine, which also can result in pain and weakness.

Findings, especially in the elderly population, focused on degenerative disorders of the aging spine including disc and facet degeneration, facet hypertrophy and loss of bone mass over time as contributors to compromised biomechanics and ROM loss [26]. Finally, in the general category, degeneration was again a theme with focus on poor cellular nutrition in cartilaginous tissues being the primary cause of tissue degeneration resulting in OA (in the case of articular cartilage degeneration) or disc degeneration especially of the intervertebral discs [34], both leading to back pain and loss of ROM.

The process of aging affects all of the body systems including the spine. The literature links loss of bone density and flexibility to increased risk for postural changes and disc fractures that contribute to loss of range of motion and participation in activities of daily living.
Quality of life is affected as aging populations experience decreased mobility due to age-related changes in spinal health. Information found, especially relating to collagen, points to physical and biochemical changes to collagenous frameworks with increased age resulting in decreased extensibility especially in aging skeletal muscle. Collagenous structural changes, regardless of type, cause degenerative effects in the mechanical properties of bone, tendons, ligaments and cartilage.

Aging affects intervertebral disks, endplates, facet joints, muscles and ligaments. This can lead to degenerative conditions such as disc degeneration, loss of bone mass, facet degeneration, bulging discs, facet hypertrophy and ligamentum flavum hypertrophy. Athletic, clinical, general and elderly populations experience these changes in various ways depending on age, activity level, and genetic disposition, with the major commonality being compromised biomechanics and loss of range of motion. Aging bone in shows an increased risk for development of osteoporosis thereby increasing the risk for stress fractures, especially in older females.

The limitations to the present study was the lack of available research into the ageing human spine as related to different populations and ROM. Continued research into the process of spinal aging, and how it affects range of motion and quality of life, with particular focus on the spinal segments, surrounding muscles, vertebrae and discs, is warranted based on this review. Further research will enable an increasingly aging population worldwide to benefit from findings. The overall goal is to promote spinal health and identify preventive and therapeutic interventions that will increase or maintain spinal range of motion, thereby allowing individuals to continue participation in activities of daily living and to enjoy an overall increased quality of life.

\section{References}

1. Chen AL, Mears SC, Hawkins RJ (2005) Orthopaedic care of the aging athlete. $J$ Am AcadOrthopSurg 13: 407-416. [Crossref]

2. Miyakoshi N, Hongo M, Maekawa S, Ishikawa Y, Shimada Y, et al. (2005) Factors related to spinal mobility in patients with postmenopausal osteoporosis. Osteoporosis Int 16(12): 1871-1874.

3. Wallmann HW (2009) Stretching and flexibility in the aging adult. Home Health Care Manag Pract 21(5): 355-357.

4. Jackson A, Gu W (2009) TRANSPORT PROPERTIES OF CARTILAGINOUS TISSUES. CurrRheumatol Rev 5: 40. [Crossref]

5. Fell J, Williams D (2008) The effect of aging on skeletal-muscle recovery from exercise: possible implications for aging athletes. J Aging Phys Act 16: 97-115. [Crossref]

6. Yukawa Y, Kato F, Suda K, Yamagata M, Ueta T (2012) Age-related changes in osseous anatomy, alignment, and range of motion of the cervical spine. Part I: Radiographic data from over 1200 asymptomatic subjects. Spine J 21: 1492-1498.

7. Zioupos P, Currey JD, Hamer AJ (1999) The role of collagen in the declining mechanical properties of aging human cortical bone. J Biomed Mater Res 45: 108-116. [Crossref]

8. Avery NC, Bailey AJ (2005) Enzymic and non-enzymic cross-linking mechanisms in relation to turnover of collagen: relevance to aging and exercise. Scand J Med Sci Sports 15: 231-240. [Crossref]

9. Bailey AJ, Paul RG, Knott L (1998) Mechanisms of maturation and ageing of collagen. Mech Ageing Dev 106: 1-56. [Crossref]

10. Intolo P, Milosavljevic S, Baxter DG, Carman AB, Pal P, et al. (2009) The effect of age on lumbar range of motion: a systematic review. Man Ther 14: 596-604. [Crossref]

11. Charlifue S, Post MW, Biering-Sørensen F, Catz A, Dijkers M, et al. (2012) International Spinal Cord Injury Quality of Life Basic Data Set. Spinal Cord 50: 672-675. [Crossref]

12. McCormack M, Briggs J, Hakim A, Grahame R (2004) Joint laxity and the benign joint hypermobility syndrome in student and professional ballet dancers. $J$ Rheumatol 31: 173-178. 
13. Phrompaet S, Paungmali A, Pirunsan U, Sitilertpisan P (2011) Effects of Pilates training on lumbo-pelvic stability and flexibility. Asian J Sports Med 2: 16-22.

14. Menard D, Stanish WD (1989) The aging athlete. Am J Sports Med 17: 187-196. [Crossref]

15. Nattrass CL, Nitschke JE, Disler PB, Chou MJ, Ooi KT (1999) Lumbar spine range of motion as a measure of physical and functional impairment: an investigation of validity. ClinRehabil 13: 211-218. [Crossref]

16. Wong KW, Leong JC, Chan MK, Luk KD, Lu WW (2004) The flexion-extension profile of lumbar spine in 100 healthy volunteers. Spine $J 29$ : 1636-1641.

17. Beighton PH, Grahame R, Bird HA (1989) Hypermobility of Joints, 2nd ed. Berlin/ Heidelberg; Springer-Verlag.

18. Meltzer KR, Cao TV, Schad JF, King H, Stoll ST, et al. (2010) In vitro modeling of repetitive motion injury and myofascial release. J Bodyw MovTher 14: 162-171. [Crossref]

19. Fitzgerald GK, Wynveen KJ, Rheault W, Rothschild B (1983) Objective assessment with establishment of normal values for lumbar spinal range of motion. Phys Ther 63: $1776-1781$.

20. Day H, Koutedakis Y, Wyon MA (2011) Hypermobility and dance: A review. Int $J$ Sports Med 32: 485-489.

21. Borg-Stein J, Elson L, Brand E (2012) The aging spine in sports. Clin Sports Med 31: 473-486. [Crossref]

22. Troke M, Moore AP, Maillardet FJ, Hough A, Cheek E. A new, comprehensive normative database of lumbar spine ranges of motion. Clin Rehabil 15: 371-379.

23. Cupon LN, Jahn WT (2003) Current standards for measuring spinal range of motion for impairment. J Chiropr Med 2: 8-12. [Crossref]

24. Benjamin M, Toumi H, Ralphs JR, Bydder G, Best TM, et al. (2006) Where tendons and ligaments meet bone: Attachment sites ('entheses') in relation to exercise and/ or mechanical load. J Anat 208: 471-490.

25. Solomon R, Solomon J, Minton S (2005) Spinal Problems in Dancers. Wright JP, Blakely JE, Preventing dance injuries (2nd ed.), IL, Human Kinetics, 91-92. Spinal Proble 5: 91-92.

26. Peterson JR (2011) Dance medicine: Head to toe: A dancer's guide to health. Hightstown, NJ: Princeton Book Company.

27. Alves de Araújo ME, Bezerra da Silva E, Bragade Mello D, Cader SA, Shiguemi Inoue Salgado A, Dantas EHM (2012) The effectiveness of the Pilates method: Reducing the degree of non-structural scoliosis, and improving flexibility and pain in female college students. J Bodyw Mov Ther 16: 191-198.

28. Papadakis M, Sapkas G, Papadopoulos EC, Katonis P (2011) Pathophysiology and biomechanics of the aging spine. Open Orthop J 5: 335-342. [Crossref]

29. Ferguson SJ, Steffen T (2003) Biomechanics of the aging spine. Eur Spine $J 12$ Suppl 2: S97-97S103. [Crossref]

30. Wightman S (2005) Lumbosacral injuries in classical ballet dancers: A review of the literature. University of Tennessee at Chattanooga Physical Therapy 1-3.

31. Rajasekaran S, Venkatadass K, Babu J, Ganesh K, Shetty AP(2008) Pharmacological enhancement of disc diffusion and differentiation of healthy, ageing and degenerated discs: Results from in-vivo serial post-contrast MRI studies in 365 human lumbar discs. Eur Spine J 17: 626-643.

32. Singh K, Masuda K, Thonar E, An H, Cs-Szabo G (2009) Age-related changes in the extracellular matrix of nucleus pulposus and annulus fibrosus of human intervertebral disc. Spine J 34(1): 10-16.

33. Yukawa Y, Kato F, Suda K, Yamagata M, Ueta T (2012) Age-related changes in osseous anatomy, alignment, and range of motion of the cervical spine. Part I: Radiographic data from over 1200 asymptomatic subjects. Spine J 21: 1492-1498.

34. Bailey AJ (2001) Molecular mechanisms of ageing in connective tissues. Mech Ageing Dev 122: 735-755. [Crossref]

35. Sinkov V, Cymet T (2003) Osteoarthritis: understanding the pathophysiology, genetics, and treatments. J Natl Med Assoc 95: 475-482. [Crossref]

36. Kadel NJ, Teitz CC, Kronmal RA (1992) Stress fractures in ballet dancers. Am J Sports Med 20: 445-449. [Crossref]

37. Held G (2002) Research into the aging process: A survey. $N$ Am Actuar J 6(3): 30-37.

38. Robinson ME, O'Connor P, Shirley FR, Mac Millan M (1993) Intrasubject reliability of spinal range of motion and velocity determined by video motion analysis. Phys Ther 73(9): 626-631.

39. Amorim T, Sousa F, Dos Santos J (2011) Influence of Pilates training on muscular strength and flexibility in dancers. Motriz: $J$ Phys Ed 17(4): 660-666.
40. Apostolopoulos N: Microstretching. A new recovery regeneration technique. New Stud Athl 2004;19(4): 47-56.

41. Busscher I, van Dieën JH, Kingma I, van der Veen AJ, Verkerke GJ, et al. (2009) Biomechanical characteristics of different regions of the human spine: an in vitro study on multilevel spinal segments. Spine (Phila Pa 1976) 34: 2858-2864. [Crossref]

42. Castro JL, Medina-Carnicer R, Galisteo AM (2006) Design and evaluation of a new three-dimensional motion capture system based on video. Gait Posture 24: $126-129$.

43. Curran PF, Fiore RD, Crisco JJ (2008) A comparison of the pressure exerted on soft tissue by 2 myofascial rollers. J Sport Rehabil 17(4): 432

44. Frankel V, Nordin M (2012) Basic Biomechanics of the Musculoskeletal System, 4th ed. Baltimore: Lippincott Williams and Wilkins.

45. Garrido-Castro JL, Medina-Carnicer R, Schiottis R, Galisteo AM, CollantesEstevez E, et al. (2012) Assessment of spinal mobility in ankylosing spondylitis using a video-based motion capture system. Man Ther 17: 422-426.

46. Gelabert R (1986) Dancers' spinal syndromes. J Orthop Sports Phys Ther 7: 180191. [Crossref]

47. Greer N, Mosser G, Logan G, Halaas GW (2000) A practical approach to evidence grading. Jt Comm J QualImprov 26: 700-712. [Crossref]

48. Hamerman D (1997) Aging and the musculoskeletal system. Ann Rheum Dis 56: 578-585. [Crossref]

49. Hammer W (2000) Integrative fascial release and functional testing Australasian Chiropractic \& Osteopathy. JCOCA 9: 13-16.

50. Huber M, Trattnig S, Lintner F (2000) Anatomy, biochemistry, and physiology of articular cartilage. Invest Radiol 35: 573-580. [Crossref]

51. Inoue N, Espinoza Orías AA (2011) Biomechanics of intervertebral disk degeneration. OrthopClin North Am 42: 487-499, vii. [Crossref]

52. Kahn K, Warren M, Stiehl A, McKay H, Wark J (1999) Bone mineral density in active and retired ballet dancers. J Dance Med Sci 3: 15-23.

53. Klemp P, Learmonth ID (1984) Hypermobility and injuries in a professional ballet company. Br J Sports Med 18: 143-148. [Crossref]

54. Knight I (2008) An insider's guide to hypermobility syndrome. J Sport Rehabil 17(4): 432-442.

55. Kujala UM, Oksanen A, Taimela S, Salminen JJ (1997) Training does not increase maximal lumbar extension in healthy adolescents. ClinBiomech (Bristol, Avon) 12: 181-184. [Crossref]

56. Loeser RF (2010) Age-related changes in the musculoskeletal system and the development of osteoarthritis. ClinGeriatr Med 26: 371-386. [Crossref]

57. Nitschke JE, Nattrass CL, Disler PB, Chou MJ, Ooi KT (1999) Reliability of the american medical association guides' model for measuring spinal range of motion: Its implication for whole-person impairment rating including commentary by Hazard R. Spine 24: 262-268.

58. Roussel NA, Nijs J, Mottram S, Van Moorsel A, Truijen S, et al. (2009) Altered lumbopelvic movement control but not generalized joint hypermobility is associated with increased injury in dancers. A prospective study. Man Ther 14: 630-635.

59. Russell P, Pearcy MJ, Unsworth A (1999) Measurement of the range and coupled movements observed in the lumbar spine. Br J Rheumatol 32: 490-497.

60. Saíz-Llamosas JR, Fernández-Pérez AM., Fajardo-Rodríguez MF, Pilat A, ValenzaDemet G, et al. (2009) Changes in neck mobility and pressure pain threshold levels following a cervical myofascial induction technique in pain-free healthy subjects. $J$ Manipulative Physiol Ther 32: 352-357.

61. Shedden M, Kravitz L (2006) Pilates exercise: A research-based review. J Dance Med Sci 10: 111-116.

62. Steinberg N, Hershkovitz I, Peleg S, Dar G, Masharawi Y, et al. (2006) Range of joint movement in female dancers and non-dancers aged 8 to 16 years. Am J Sports Med 34: 814-823.

63. Stone J (2000) Myofascial release. Athl Ther Today 5(4): 34-35.

64. Trepman E, Micheli L (1988) Overuse injury in sports. Sem Orthop 3: 217-222.

65. Weiler C, Nerlich A, Schaaf R, Bachmeier BE, Wuertz K, et al. (2010) Immunohistochemical identification of notochordal markers in cells in the aging human lumbar intervertebral disc. Eur Spine J 19: 1761-1770.

66. Wyon MA, Felton L, Galloway S (2009) A comparison of two stretching modalities on lower limb range of motion measurements in recreational dancers. $J$ Strength Cond Res 23(7): 2144-2148.

\section{Citation:}

Janine Bryant, Jeff Russell, Yiannis Koutedakis, and Matthew Wyon (2018) The Effect of Age on Spinal Range of Motion: A Review. Ageing Sci Ment Health Stud Volume 2(3): 1-7 